\title{
A numerical model study on the behaviour of Asian summer monsoon and AMOC due to orographic forcing of Tibetan Plateau
}

\author{
Bijan Fallah $^{1} \mathbb{1} \cdot$ Ulrich Cubasch $^{1} \cdot$ Kerstin Prömmel $^{1} \cdot$ Sahar Sodoudi $^{1}$
}

Received: 25 November 2014 / Accepted: 13 November 2015 / Published online: 28 November 2015

(C) The Author(s) 2015. This article is published with open access at Springerlink.com

\begin{abstract}
Simulations using the ECHAM5/MPI-OM coupled atmosphere-ocean model both with and without the Tibetan Plateau are performed in order to study the large scale effects of orographic forcing on the behaviour of the Asian summer monsoon system. Our analysis emphasises the significant impact of plateau forcing on the atmosphere-ocean interactions. It is argued that, in addition to the orographic forcing of the Tibetan Plateau on the climate of Asia such as sensible heat pumping and thermal insulation, other significant direct processes exist, which link the Asian summer monsoon to the sea surface temperatures in the North Atlantic Ocean. The removal of the Tibetan Plateau modifies the wind-driven ocean circulations over the North Atlantic, which leads to a decrease in the surface heat advection over the North Atlantic Ocean and a decrease in the Atlantic Meridional Overturning Circulation. This, in turn, affects, via teleconnections, both the monsoon rainfall and the position of the intertropical convergence zone.
\end{abstract}

Keywords Tibetan Plateau · Orographic forcing · Asian summer monsoon $\cdot$ Atmosphere-ocean teleconnections

Electronic supplementary material The online version of this article (doi:10.1007/s00382-015-2914-5) contains supplementary material, which is available to authorized users.

Bijan Fallah

bijan.fallah@met.fu-berlin.de

1 Institute of Meteorology, Freie Universität Berlin, Carl-Heinrich-Becker Weg 6-10, 12165 Berlin, Germany

\section{Introduction}

The Tibetan Plateau (TP) is a vast elevated plateau in Central Asia with an average elevation of 4,500 meters. It has long been established textbook knowledge that the Asian summer monsoon is associated with the direct sensible heating over the TP (Flohn 1968; Yanni and Wu 2006). Although recent theoretical studies and numerical experiments have questioned this concept (Boos and Kuang 2010, 2013; Park et al. 2011; Rajagopalan and Molnar 2013; Saito et al. 2006; Tang et al. 2011, 2013a, b; Wu et al. 2012; Yasunari et al. 2006), there is still controversy regarding the role of the TP in driving the Asian summer monsoon system.

Several studies applied Atmosphere-only General Circulation Models (AGCM) (Boos and Kuang 2010; Chakraborty et al. 2002; Wu et al. 2012; Yasunari et al. 2006) or Atmosphere-Ocean General Circulation Models (AOGCM) (Boos and Kuang 2013; Park et al. 2011; Tang et al. 2013b) to investigate the Asian summer monsoon behaviour caused by the orographic forcing of the TP. For example, Boos and Kuang $(2010,2013)$ showed that the heating of the TP locally affects the precipitation over the Himalayas but has no impact on the large-scale monsoon circulations, demonstrating that, during the summer, the Himalayan topography acts as a barrier to shield the warm and moist southern Asian monsoon region from the cold and dry extra-tropical air masses. They concluded that, during summer, the maximum upper tropospheric temperatures occur throughout the Indian sub-continent, rather than over the TP. In contrast to Boos and Kuang (2010, 2013), Wu et al. (2012) suggested that South and East Asian monsoons are controlled by the thermal forcing of the different parts of the TP, and that the mechanical effect of the plateau is not the major driver of the Asian summer monsoon. The models applied in the studies of Boos and Kuang (2010) 
and $\mathrm{Wu}$ et al. (2012) were integrated using the prescribed climatological Sea Surface Temperature (SST) and sea ice. This approach may be insufficient to demonstrate the indirect impact of the orographic modifications on the ocean circulation (Boos and Kuang 2010). The integration period of the coupled atmosphere-ocean simulation of Boos and Kuang (2013) was limited to 25 years. Additional studies are therefore needed to investigate the ocean response to orographic forcing by using longer integrations of coupled atmosphere-ocean models.

To discover the high-resolution patterns of the Asian summer monsoon, Tang et al. (2013b) applied a regional climate model which was driven by an AOGCM. They showed that the regional orographic uplift produces the asynchronous evolution of the Indian summer monsoon and the East Asian summer monsoon, concluding that the intensified East Asian summer monsoon is linked to the sensible heat pumping of the northern, eastern and central $\mathrm{TP}$, and that the Indian summer monsoon is enhanced by thermal insulation. The selected AOGCM, which was used for their sensitivity experiment, had a globally lower orography except over the TP.

Apart from sensitivity experiments based on the climate model simulations, some studies have used observational and re-analysis data to study the impact of the TP on the Asian monsoon (Gu et al. 2009; Rajagopalan and Molnar 2013). Using the re-analysis data, Rajagopalan and Molnar (2013) showed that the plateau heating correlates directly with the monsoon rainfall during the early and late summer, but only marginally during the mid-June to the end of August period.

The ocean circulation is affected by the highly nonlinear variations in the atmospheric circulation. This is illustrated, for example, in the atmosphere-ocean interactions during an abrupt climate change (Rahmstorf 2002; Gu et al. 2009; Liu et al. 2013). Using the NCEP/NCAR re-analysis dataset, Ya et al. (2013) investigated the possible Eurasia-North Atlantic Ocean teleconnection. According to their results, Atlantic SST changes have a greater impact on the southern TP summer rainfall than Indo-Pacific oceans via Rossby waves. The recent IPCC report (Stocker et al. 2013) points out that global warming may lead to a cooler North Atlantic by weakening the Atlantic Meridional Overturning Circulation (AMOC). Assuming two preferred regimes (e.g., active and break) in the Asian summer monsoon (Palmer 1994; Turner and Hannachi 2010; Hannachi and Turner 2013), the break phases of the Indian monsoon coincide with a cold Northern Atlantic and Arctic, and the active phases with a warm Northern Atlantic and Arctic (Marzin et al. 2012). Thus, the AMOC, which plays a major role in transporting heat from the Southern Hemisphere and tropics towards the North Atlantic, may influence the extreme moisture changes in monsoon regions. The AMOC reduction is closely connected to the cooling of the North Atlantic. Woollings et al. (2012) estimated a temperature change of $0.31 \mathrm{~K}$ for a $1 \mathrm{~Sv}$ weakening of the AMOC in the region $20^{\circ}-60^{\circ} \mathrm{W}, 45^{\circ}-70^{\circ} \mathrm{N}$. They concluded that in a warm North Atlantic, the positive Atlantic Multidecadal Oscillation $\left(\mathrm{AMO}^{+}\right)$phase is associated with an increase in the Sahel and Indian summer monsoon rainfall. Previous studies (Vellinga and Wood 2002; Cheng et al. 2013; Chiang et al. 2008; Stouffer et al. 2006) indicated that changes in the AMOC influence the Inter-Tropical Convergence Zone (ITCZ). Stouffer et al. (2006) showed that an AMOC weakening causes an equatorward shift of the ITCZ. Thus, as a consequence of changing ITCZ, the AMOC influences the Asian monsoon regions (Zhang and Delworth 2006). The paleo records from sediment cores of the North Atlantic indicate a "shutdown" in the AMOC during the Heinrich event H1 (McManus et al. 2004). Using a stalagmite record from China, Liu et al. (2013) assessed the linkage between the North Atlantic and the monsoon system during the 8.2 $\mathrm{k}$ year event. They showed that, during this event, the climate was significantly drier than today and was connected to an abrupt cooling in the North Atlantic ocean. According to their results, this linkage is also existent in any warm climate similar to the current one. Wang et al. (2001) found a remarkable resemblance between the oxygen isotope records of stalagmites from the Hulu Cave in China and from the Greenland ice cores. They concluded that the strong East Asian monsoon is linked to warmer Greenland temperatures, while the weaker East Asian monsoon is related to cool temperatures in Greenland. The weakening of the AMOC due to global warming is more likely to be linked to changes in surface heat flux than in freshwater (Gregory et al. 2005).

The question which is still not answered in the previous studies is how the TP elevation will influence the atmosphere-ocean relation, and to what extent the atmospheric changes influence the ocean's response. Our study investigates the results of a numerical modeling experiment using the ECHAM5/MPI-OM coupled AOGCM to identify the role of the TP in the evolution of the climate system with a focus on the Asian summer monsoon. A longer integration time is chosen here to consider the feedback processes between the ocean and the atmosphere. In contrast to most of the previous studies, our model set up allows an investigation of the climatic patterns under a changing Tibetan Plateau forcing with an interactive ocean. The model set up is based on the hypothesis on the effects of the TP on the Asian summer monsoon stated above, and is described in Sect. 1. In Sect. 2 the mechanisms governing the interplay between the summer monsoon, the low-level circulations and the ocean conditions are reviewed, in order to build a basis for further investigations. Section 3 contributes to the results. Discussion and conclusions are presented in Sect. 4. 


\section{Approach and methods}

\subsection{Model configuration}

The feedback processes between ocean, atmosphere and orographic forcing are studied by designing two different simulation scenarios: (a) a simulation with present day topography as the control (CTRL) run, and (b) with decreased elevation of the TP and Central Asia (NOTP). The Community Earth System Models (COSMOS version 1.2.1) developed by the Max Planck Institute for Meteorology in Hamburg was applied in this study, which consist of the atmosphere climate model ECHAM5 version 5.4.01 (Roeckner et al. 2006) and the ocean model MPI-OM version 1.3.1 (Marsland et al. 2003). ECHAM5 was integrated at T31 resolution (corresponding to a Gaussian grid of $3.75^{\circ} \times 3.75^{\circ}$ ) with 19 vertical levels and the MPI-OM ocean model at GR30 resolution with 40 vertical levels. Both simulations are initialised using the climate state of the ensemble member mil0014 of the "millennium" simulation from the fully coupled MPI-ESM (Jungclaus et al. 2010), starting from the year $1500 \mathrm{AD}$. The model-proxy comparisons show that mil0014 has the best performance (Polanski et al. 2014). Greenhouse gas (GHG) concentrations (e.g. $\mathrm{CO}_{2}, \mathrm{~N}_{2} \mathrm{O}, \mathrm{CH}_{4}$ ) are fixed at their pre-industrial values. In both setups, the subgrid-scale orographic drag is considered, using the parameterisation scheme of Lott and Miller (1997). In the NOTP set-up, the topography of the TP is decreased by $200 \mathrm{~m}$ in every 10 -year integration period to the threshold of $500 \mathrm{~m}$ after 180 years of integration (Fig. 1). The related subgrid-scale orography parameters (surface roughness length, standard deviation of orography, slope, orientation, anisotropy, angle, peaks and valleys elevation) have been adjusted according to the scheme presented by Baines and Palmer (1990). The model simulations are integrated for 500 years and the last 50 years are used for the analysis unless otherwise mentioned.

Two additional simulations are performed with the atmosphere-only ECHAM5 model using the prescribed SST and sea ice from the CTRL and NOTP simulations. The model is integrated for 6 years and the last 2 years are analysed (first 4 years are excluded as spin-up). The data adjustment for interpolation of SST and sea ice from T31 to T63 resolution follows the Atmospheric Model Intercomparison Project phase 2 (AMIP2) procedure available at: http://www-pcmdi.llnl.gov/projects/amip/AMIP2EXPDSN/BCS_OBS/amip2_bcs.htm\#create_sic.

\subsection{Low-level circulation, ocean conditions and summer monsoons}

The atmospheric general circulation consists of the flow which is averaged over time long enough to eliminate the random changes related to local weather systems (Holton and Hakim 2012). Lower atmospheric circulations over the oceans can impact the large-scale precipitation patterns like the monsoons. Inversely, the heating associated with the monsoon rainfall modifies the low-level circulations over the oceans (Heckley and Gill 1984; Rodwell and Hoskins 2001). According to Rodwell and Hoskins (2001) (hereafter, $\mathrm{RH}$ ), during wintertime, the subtropical circulation is strongly dominated by the zonal mean flow and its interactions with the orography. In the Northern Hemisphere summer, the low-level circulation over the subtropical oceans is characterised by subtropical highs (anticyclones in Fig. 2b). According to Anderson and Gill (1975), the wind stress curl related to these subtropical highs drives the subtropical gyres. RH showed that the subtropical highs (anticyclones) also affect the global teleconnection patterns such as the North Atlantic oscillation. There is a clear interplay between the monsoons, the subtropical anticyclones and the global atmosphere-oceans interaction. RH concluded that the summertime anticyclone easterlies over the North Pacific are linked to the Asian summer monsoon heating and demonstrated that the subtropical descent over the North Pacific and the North Atlantic is induced by North American and Asian monsoon, respectively. The year-long colder eastern subtropical oceans support the atmospheric descent. On the other hand, the descent itself is followed by equator-ward winds which lead to the upwelling of cold deeper water over the eastern subtropical oceans via
Fig. 1 Topography (metre) for a CTRL and b NOTP (final state) simulations (a) CTRL

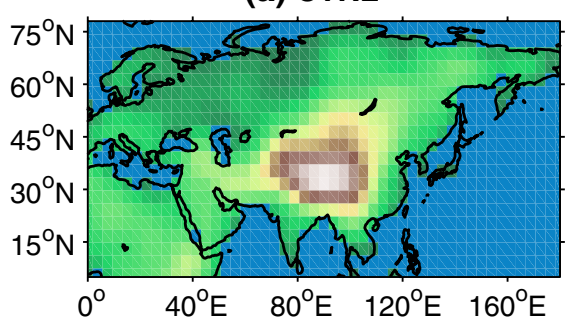

(b) NOTP

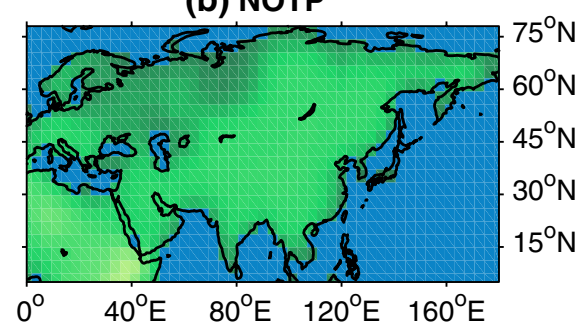

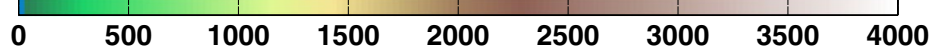


the wind-driven Ekman pumping. Over the western subtropical oceans, the poleward Sverdrup transport leads to the Ekman suction. RH discussed how the Earth's major topographic features play a major role in localisation of the descent east of the subtropical highs.
In frictionless barotropic conditions, the atmospheric response to the orographic forcing depends on the mountain scale (Wu 1984). According to Wu (1984), most of the atmospheric response to large-scale topographic features (higher than "critical mountain height" of $1 \mathrm{~km}$ ) is
Fig. 2 Large scale patterns of a summer (JJAS) Precipitation minus Evaporation ( $\mathrm{mm} /$ day) for CTRL, b $500 \mathrm{hPa} . \omega\left(\mathrm{Pas}^{-1}\right)$ and $850 \mathrm{hPa}$ wind $\left(\mathrm{ms}^{-1}\right)$ for CTRL, $\mathbf{c}$ precipitation minus evaporation ( $\mathrm{mm} /$ day) difference of NOTP compared to CTRL (CTRL-NOTP), and d $500 \mathrm{hPa} \omega\left(\mathrm{Pas}^{-1}\right)$ and 850 $\mathrm{hPa}$ wind $\left(\mathrm{ms}^{-1}\right)$ difference of NOTP compared to CTRL (CTRL-NOTP). The largest vector in (b) is $12 \mathrm{~ms}^{-1}$ and in (d) is $6 \mathrm{~ms}^{-1}$ (a) P-E for CTRL

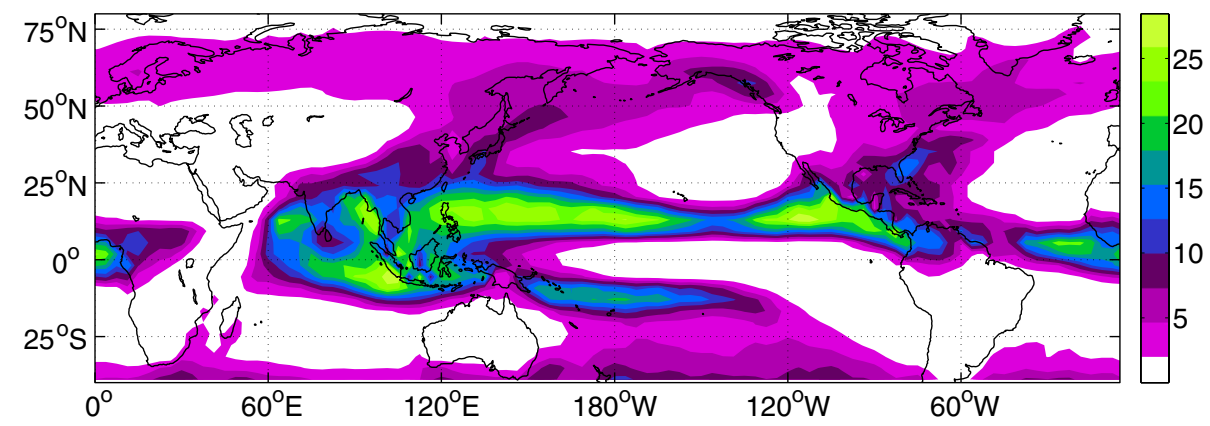

(b) $500 \mathrm{hPa} \omega$ and $850 \mathrm{hPa}$ Wind for CTRL

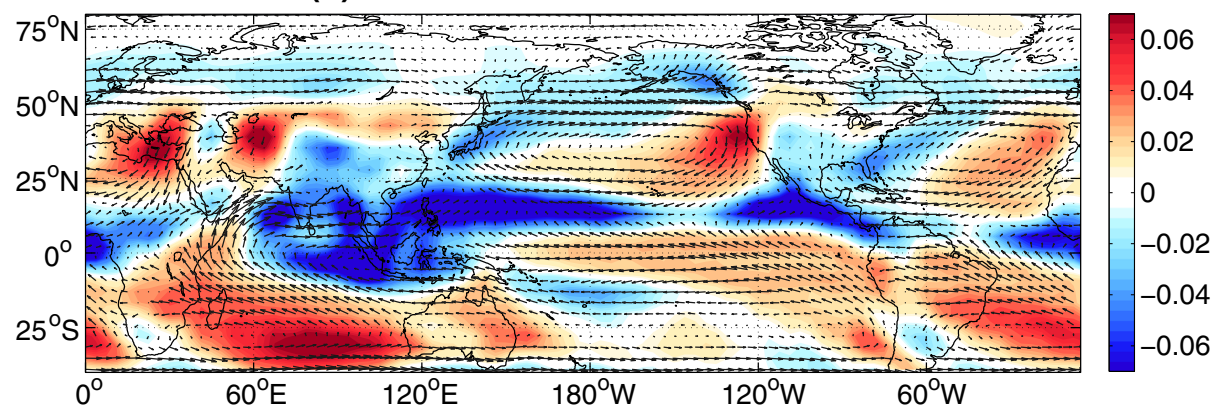

(c) P-E for CTRL-NOTP

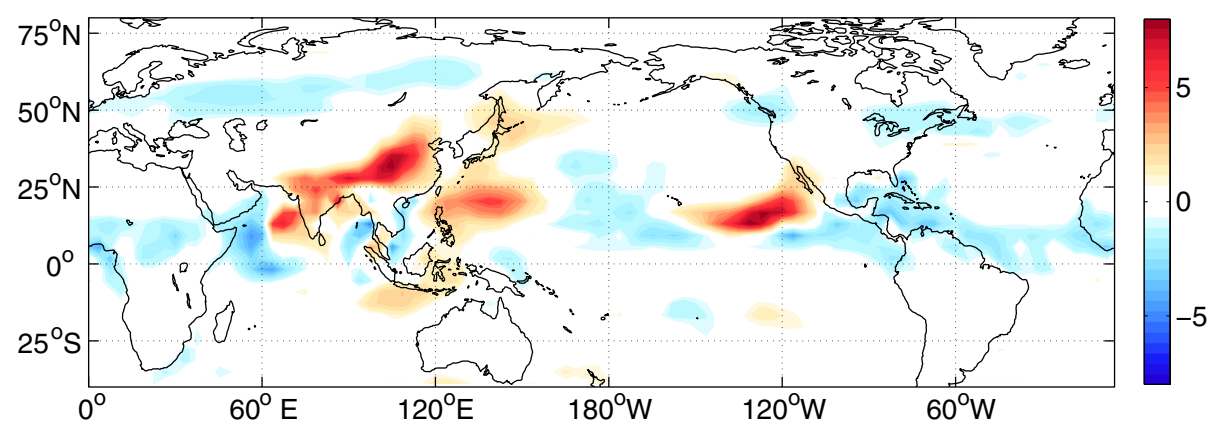

(d) $500 \mathrm{hPa} \omega$ and $850 \mathrm{hPa}$ Wind for CTRL-NOTP

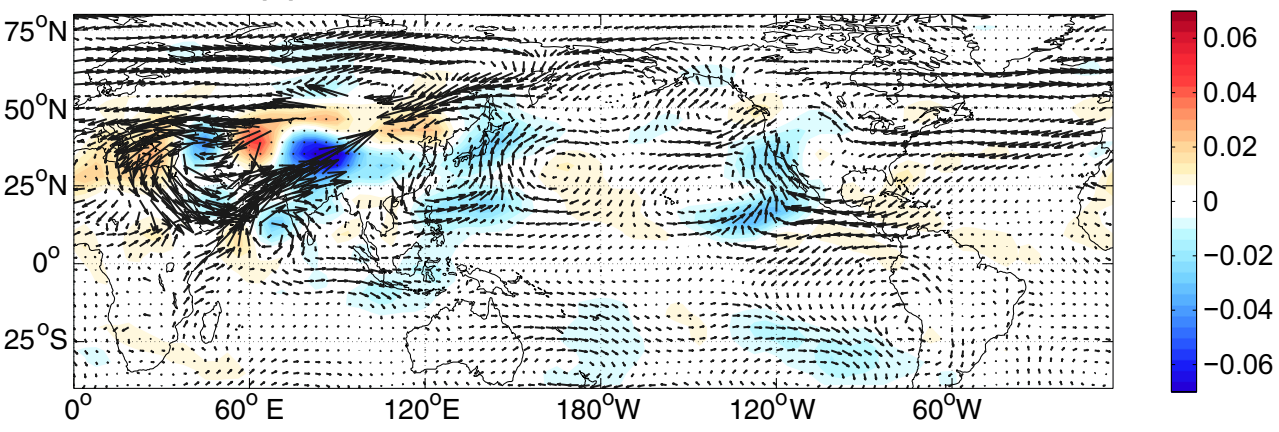


non-linear and the mechanically-forced surface anticyclone is located upstream of the orography. The mid-latitude topography plays a major role in the formation of Rossby waves (Hoskins and Karoly 1981; Held and Ting 1990; Saulire et al. 2011), which can influence the air flows as far as very remote areas and alter the wind field pattern throughout the hemisphere. Previous studies confirmed the linkage between the North Atlantic and Eurasia via the wave trains (Bothe et al. 2011; Sun and Wang 2012; Ya et al. 2013). According to Ding and Wang (2005), the summer wave train (e.g., circumglobal teleconnection pattern) originates in Europe and the North Atlantic region which facilitates the low-level ascending air motions over India. As mentioned by Holton and Hakim (2012), a quantitative study of the general circulation requires complex numerical models which solve the spherical primitive equations.
Given that there is a linkage between the summer monsoon, the low-level circulations and the ocean conditions, the challenging question is how does the orographic forcing impact such interactions.

\section{Results}

\subsection{Simulation of present day conditions}

The state-of-the-art IPCC AR5 models can generally provide accurate estimates of the current climate. Among them, the ECHAM5/MPI-OM shows a relatively good performance in reproducing the interannual variation and mean of the Asian summer monsoon (Kripalani et al. 2007a, b). Using this motivation, the possible state of the climate

(a) AMOC (Sv) for CTRL-NOTP

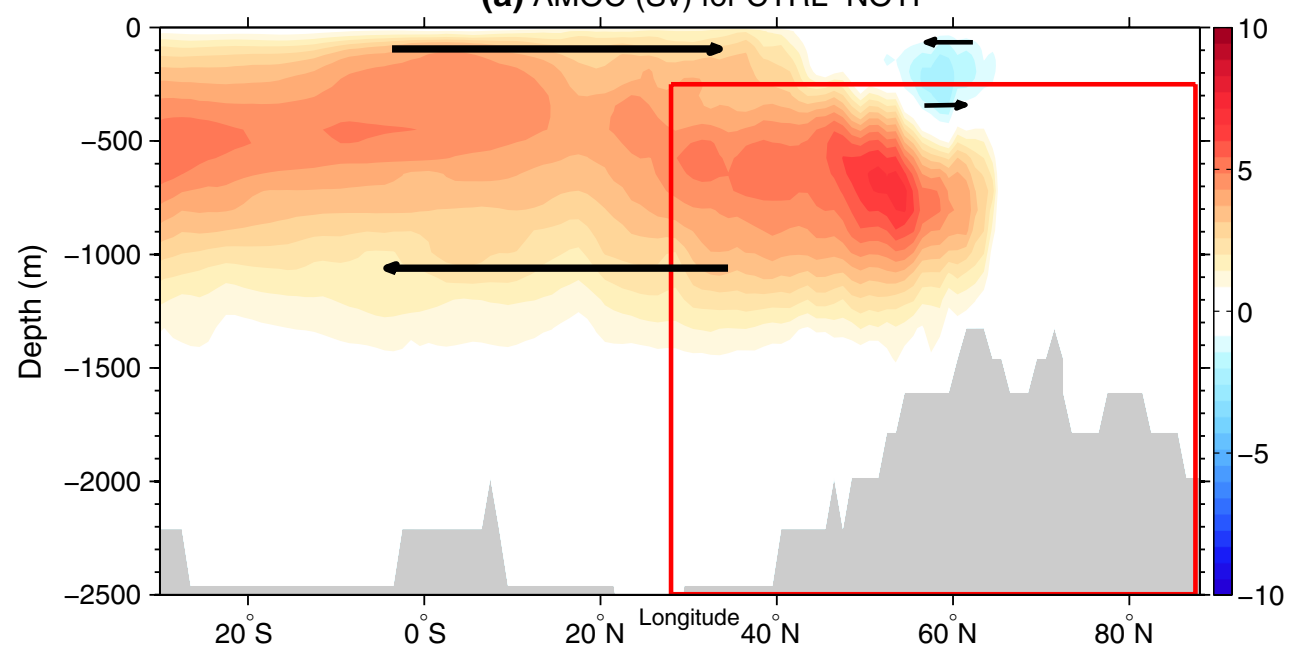

(b) AMOC index

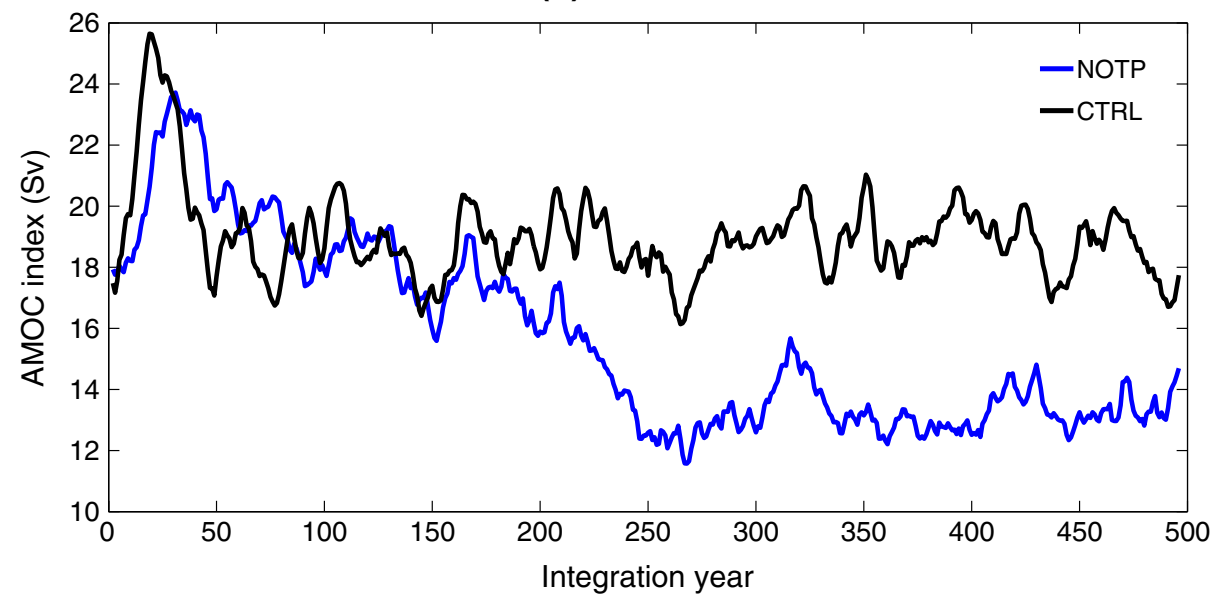

Fig. 3 a North Atlantic averaged meridional overturning stream function difference (Sv) between CTRL and NOTP (CTRL-NOTP) and $\mathbf{b}$ time-series of AMOC for NOTP (blue) and CTRL (black). The maximum value inside the red box is defined as AMOC index for each time-step. Positive values indicate anticyclonic circulations 
(temporally averaged patterns of temperature, wind, precipitation and other variables) in the absence of the Tibetan Plateau is presented here. Prior to applying the model for the sensitivity experiment, its ability to reproduce the Asian summer monsoon patterns for precipitation and temperature is tested (supplementary material). The model-data comparison shows that the model is skillful in reproducing the mean climatological state of the rainfall and temperature patterns throughout the Asian monsoon domain. Figure 2a shows the mean summer (JJAS) precipitation minus evaporation (P-E) for CTRL. The global picture of the summer monsoon is well represented by this simulation (see also Sect. 3.3). Figure $2 \mathrm{~b}$ shows $500 \mathrm{hPa} \omega$ as a proxy for the ascending $(\omega<0)$ and descending $(\omega>0)$ motions superposed on the $850 \mathrm{hPa}$ wind field. Comparing the two figures reveals that the maximum rainfall values are located over the upward motion regions (convective precipitation). There are two large-scale anticyclonic circulations over the North Pacific Ocean and in the North Atlantic Ocean (Fig. 2b). The $500 \mathrm{hPa} \omega$ pattern over the Pacific shows a descending centre over the east North Pacific and an ascending region over the west equatorial Pacific. The easterly winds in $850 \mathrm{hPa}$ connect these two regions and generate the trade winds over the Pacific. The anticyclone over the North Atlantic consists of a descending region over the east and an ascending area over the west North Atlantic. These anticyclones may originate from the land-sea distribution due to the induced various diabatic heating and not as a result of wave propagation on the lee-side of the TP (Wu and Liu 2003; Liu et al. 2004; $\mathrm{Wu}$ et al. 2009). The influence of the TP on the monsoon circulation is studied in the next section by a simulation of conditions without the TP.

\section{(a) SST (CTRL-NOTP)}

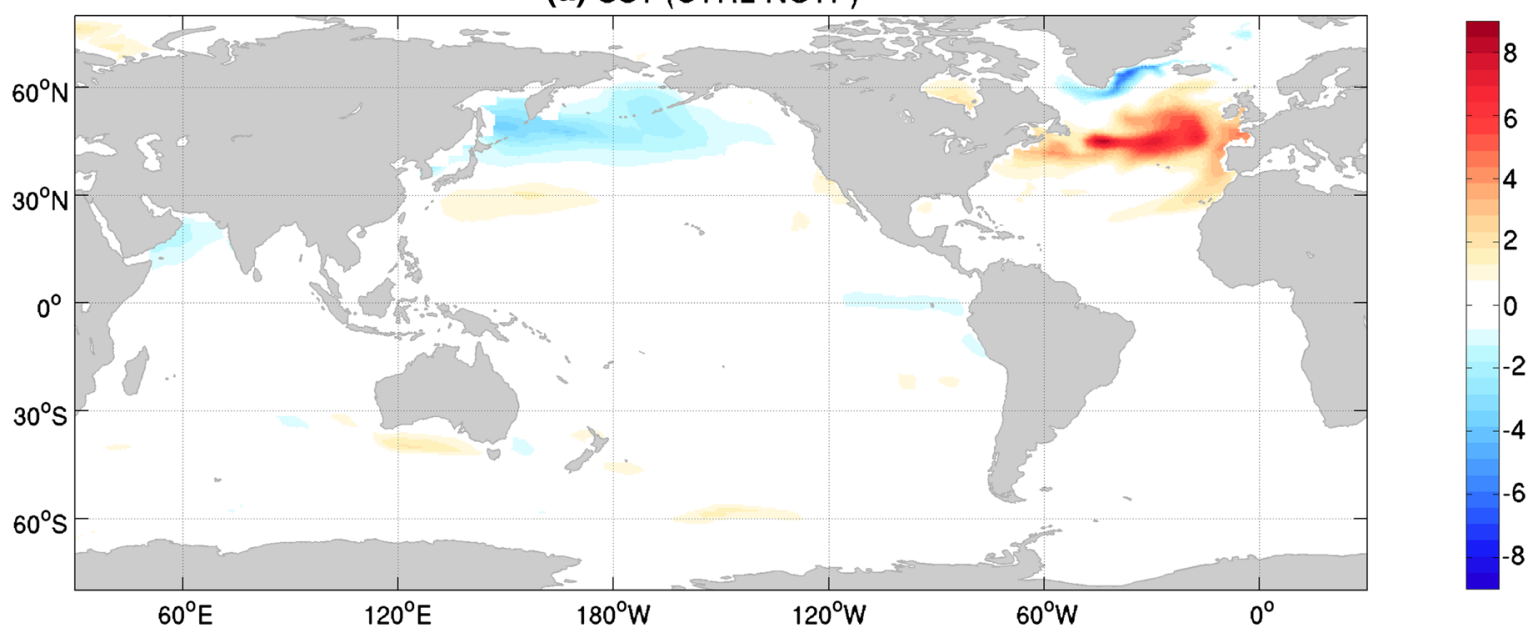

(b) Ocean temperature CTRL

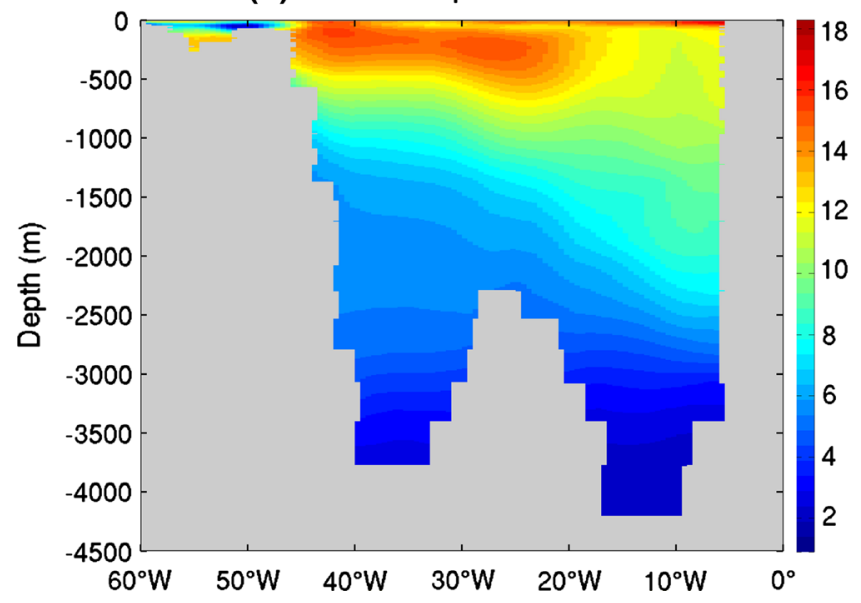

(c) Ocean temperature (CTRL-NOTP)

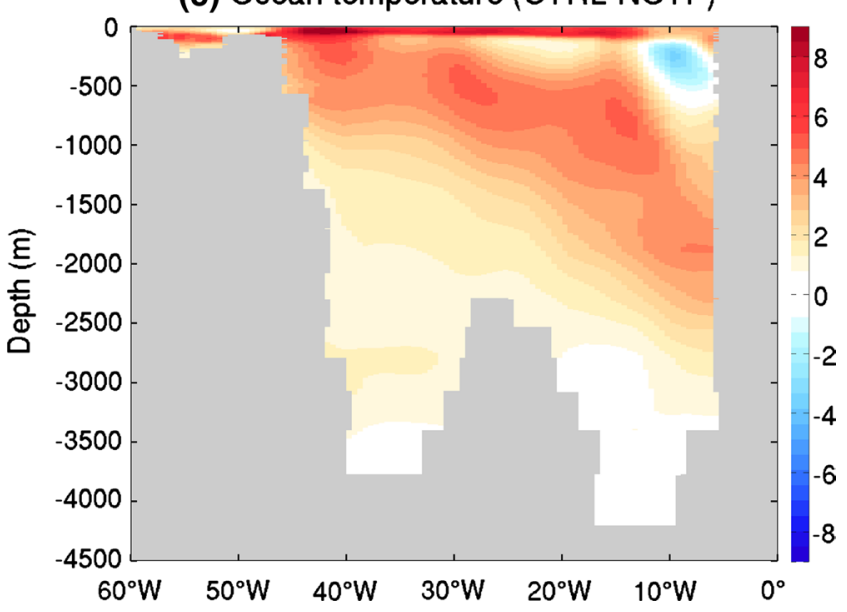

Fig. 4 Large scale patterns of a climatology of summer (JJAS) SST $\left({ }^{\circ} \mathrm{C}\right)$ differences for CTRL-NOTP, b cross section of North Atlantic Ocean's temperature $\left({ }^{\circ} \mathrm{C}\right)$ and $\mathbf{c}$ cross section of the North Atlantic Ocean's temperature difference (CTRL-NOTP) at $45^{\circ} \mathrm{N}$ 


\subsection{Simulation of conditions without Tibetan Plateau}

Subtracting the general state of the climate in the two different simulations (CTRL - NOTP) highlights the topographic effect of the TP on the climate patterns.

As can be seen in Fig. 2c (and Sect. 3.3), a large portion of the Asian summer monsoon P-E is reduced in the NOTP. Over the east equatorial Pacific Ocean (around $120^{\circ}$ $\mathrm{W}$ and $20^{\circ} \mathrm{N}$ ), atmospheric deep convection is reduced and shifted towards the Central Pacific and the American continent. The largest patterns which are altered in the NOTP are the reduced ascending motions over the Asian monsoon region with a peak over the TP and the weaker Somali Jet (Fig. 2d). The reduced large cyclonic motion over the Middle East is mainly due to the removal of the Iranian Plateau (IP). This is because the IP surface sensible heating generates the cyclonic circulation (Wu et al. 2012). The pronounced weakening of the Somali Jet, which transits Kenya, Somalia, Yemen and Oman, accounts for the reduction in moisture transport to the Indian monsoon region. On the lee-side of the largest topographic barrier, the TP, the alternating cyclonic and anticyclonic motions are shown in the anomaly patterns (Fig. 2d). The weakening of the trade winds in the NOTP lead to an attenuated "Walker cell" in the equatorial Pacific which accounts for a rising motion over Indonesia and a sinking one over the eastern Pacific. The $850 \mathrm{hPa}$ wind presents an anticyclonic motion in the North Atlantic (Fig.2b). The reduction of this circulation in the NOTP (Fig. 2d) influences the oceanic currents in the North Atlantic via the wind-driven ocean circulations. The anticyclonic motion over the west North Pacific, east coast of Japan, is also reduced in the NOTP.

As a response to anomalous atmospheric low level winds, convergence, precipitation and vertical motions, the ocean-atmosphere interaction alters the ocean circulation. The North Atlantic averaged meridional overturning stream function for the NOTP shows a remarkable decrease compared to the CTRL (Fig. 3a). This circulation expresses the impact of the TP on the North Atlantic circulations. The AMOC circulation pattern (its core is located at $\sim 1000 \mathrm{~m}$ depth and $55^{\circ} \mathrm{N}$ ) leads to downwelling of warm surface water into the deeper ocean layers around $40^{\circ} \mathrm{N}$. To assess the AMOC changes, the AMOC index is calculated based upon the maximum value of meridional overturning stream function north of $28^{\circ} \mathrm{N}$ within the red box in Fig. 3a (Hofer et al. 2011). The AMOC indices of the CTRL and the NOTP are shown in Fig. 3b. There is a clear drop of about 6 $\mathrm{Sv}$ in the AMOC when the TP is removed. The weakening of the AMOC is connected to the weakening of the North Atlantic anticyclone and the reduced heat advection from

(a) P-E for CTRL

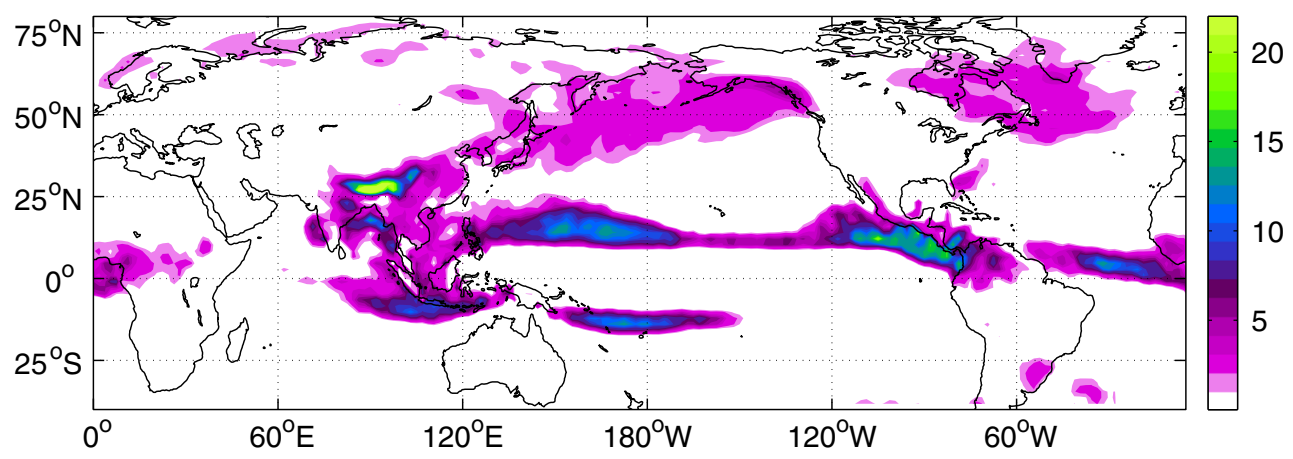

(b) P-E for CTRL-NOTP

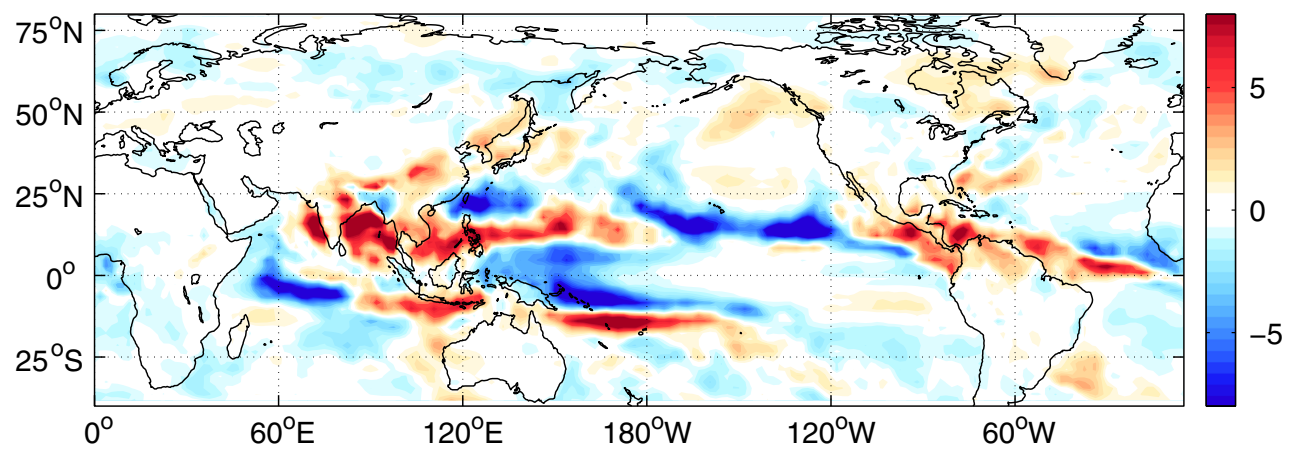

Fig. 5 Large scale patterns of a summer (JJAS) P-E (mm/day) from CTRL ECHAM5 AGCM simulation b summer (JJAS) P-E (mm/day) differences for CTRL-NOTP 

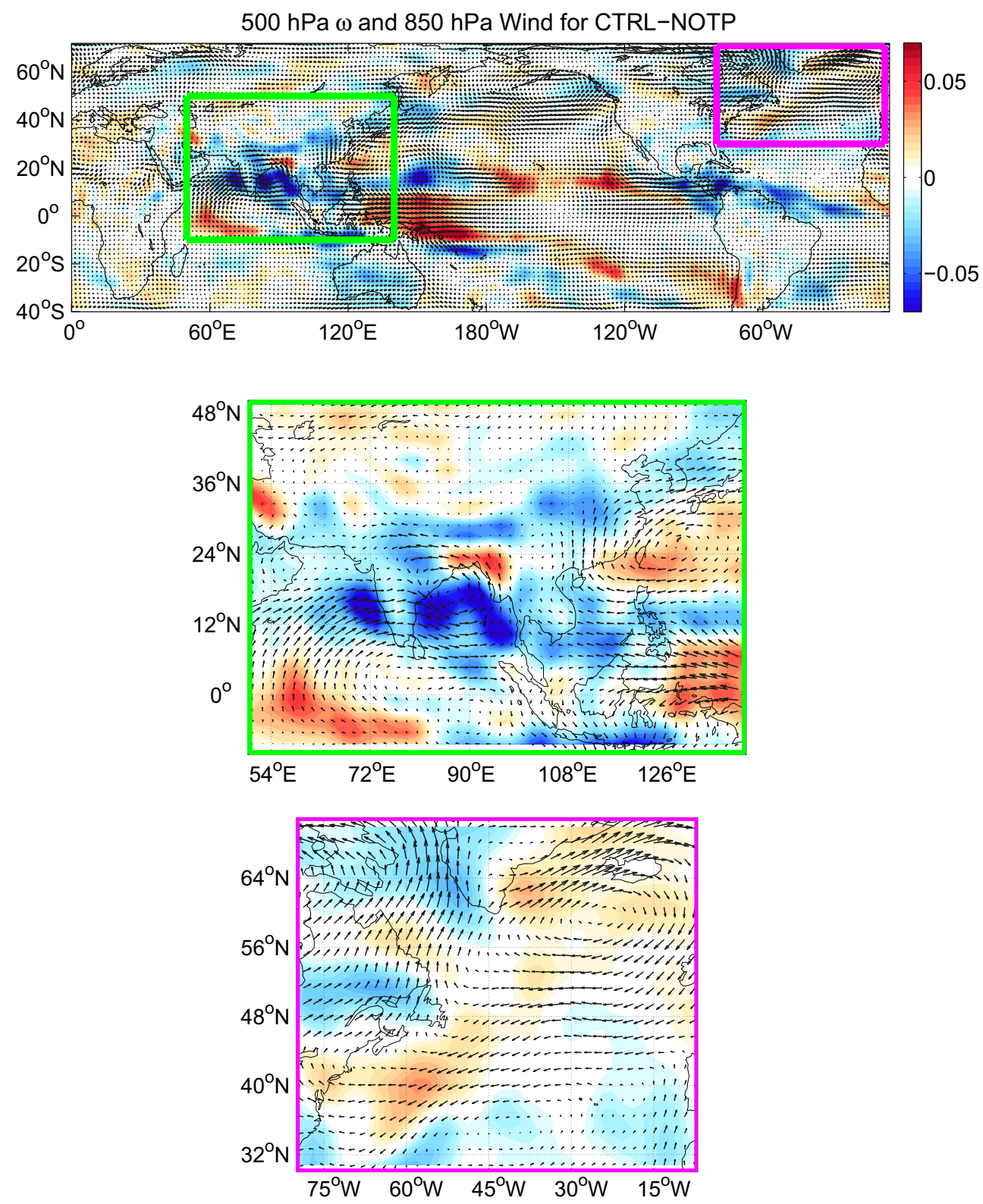

Fig. 6 Large scale patterns of summer (JJAS) $500 \mathrm{hPa} \omega$ and $850 \mathrm{hPa}$ wind for CTRL-NOTP ECHAM5 AGCM simulations. Largest wind vector is $13.25 \mathrm{~ms}^{-1}$

south-western North Atlantic regions to the north-eastern part. This leads to a cooling of the North Atlantic (Fig. 4).

The impact of the removal of the TP is apparent in SST patterns mainly in the North Atlantic and to a lesser extent in the North Pacific (Fig. 4a). The North Atlantic Ocean is remarkably warmer in the CTRL than in the NOTP (up to 8 $\mathrm{K})$. This can influence the monsoon via the teleconnection between the North Atlantic and the Asian monsoon, which is discussed in Sect. 3.3.

Figure $4 \mathrm{~b}$ shows the climatology of ocean temperature in the longitude-depth plane at $45^{\circ} \mathrm{N}$. In the CTRL, a warm water current, which initiates from the surface over the
Western North Atlantic Ocean (around $45^{\circ} \mathrm{W}$ ), penetrates to the deeper layers down to $2000 \mathrm{~m}$ depth at $10^{\circ} \mathrm{W}$. This warm current is reduced when the large-scale topography of the TP is removed (Fig. 4c).

\subsection{Direct linkage between AMOC, North Atlantic SSTs and Asian summer monsoon}

Liu et al. (2013) suggested that there was a rapid teleconnection between the North Atlantic and the Asian summer monsoon. This teleconnection is not a result of a baroclinic adjustment in the oceans. They concluded that these changes 
in the North Atlantic ocean circulation may be damped as they reach the Pacific and Indian oceans and this relationship may originate from the atmospheric processes (Liu et al. 2013; Broccoli et al. 2006; Chiang and Bitz 2005).

In order to explore the direct impact of the AMOC and the SSTs over the North Atlantic on the Asian summer monsoon, the ECHAM5 model is run with a higher horizontal resolution of T63L31 using the SSTs and sea ice from the ECHAM5/MPI-OM coupled simulations (CTRL and NOTP). The orography is unchanged in both runs in order to consider only the impact of changing the oceanic heat transport in the Atlantic ocean on the Asian summer monsoon. Figure 5a shows the summer (JJAS) precipitation minus evaporation pattern from the ECHAM5 simulation driven by SST and sea ice data from the CTRL. This figure shows a more realistic rainfall pattern compared to the coupled simulation. The model was able to capture the rainfall over the Himalayas, which was not present in the coupled runs. This may be due to the more realistic topography of the new simulations at T63 horizontal resolution. Figure $5 \mathrm{~b}$ shows the differences of the two atmosphere-only simulations with the prescribed SST and sea ice from both coupled runs. There is a substantial decrease in the Asian summer monsoon in the ECHAM5-NOTP simulation, especially over Western Ghats, the Himalayas, East China and Indonesia.

Figure 6 presents the differences of near surface circulation patterns between the CTRL and the NOTP atmosphereonly simulations. Given that the topography is unchanged, there is a weakening of the Somali Jet and the anticyclonic pattern over the North Atlantic in the NOTP-driven ECHAM5 runs compared to normal conditions. However, the northward moisture transport from the Bay of Bengal is significantly reduced in the NOTP and the trade winds show a substantial reduction over the equatorial Pacific (Fig. 6).

These atmosphere-only simulations present the abrupt impact of altered SST conditions on the atmosphere regardless of the direct orographical forcing and thereby support the hypothesis of Liu et al. (2013). However, we encourage further investigations using longer simulation times ( $\sim 30$ years).

\section{Conclusions and discussions}

In this study, the role of the TP on the Asian summer monsoon is investigated using the coupled ECHAM5-MPI$\mathrm{OM}$ and atmosphere-only ECHAM5 models. As a result of the coarse spatial resolution of the coupled runs, these experiments are able to capture the large-scale climatological patterns of the monsoon, although its local effects are not resolved. The large-scale patterns of the Asian summer monsoon are significantly influenced by the removal of the Tibetan Plateau. In agreement to the studies of Boos and Kuang (2010) and Park et al. (2011), our results demonstrate that the large-scale Asian summer monsoon circulations are weakened notably by the removal of the TP. Boos and Kuang (2010), however, conclude that this weakening is linked to the insulator effect of the Himalayas, rather than the sensible heating effect by the TP. Our model experiment revealed that the main large-scale circulations (e.g., the Somali Jet, the trade winds and the North Atlantic anticyclones) are reduced in the absence of the TP. We find two main effects when removing the TP: 1 . The removal of the TP produces a weaker Somali Jet that normally acts as the main driver of the "moisture conveyor belt" which brings moisture to the Indian sub-continent. In the absence of the TP forcing, trade winds tend to decelerate over the North Pacific Ocean, resulting in an attenuated "Walker cell" in the equatorial Pacific. These changes contribute to a reduction of the monsoon rainfall over India and East China. 2. The removal of the TP also alters the global wave pattern, which induces a reduction of anticyclonic patterns of low-level winds in the North Atlantic Ocean. This leads to a decreased advection of near surface atmospheric heat into the North Atlantic Ocean and a drop of the sea surface temperature by about $6 \mathrm{~K}$. This leads to less transport by the atmospheric circulations and hence to a southward shift of the ITCZ and the Asian summer monsoon.

Our results point to possible direct and indirect mechanisms, in which the TP influences the climatic circulation and in particular the Indian summer monsoon. We recognise, however, that our model experiment, due to a lack of computing resources, does not have the resolution to resolve all the processes in detail. The experiment could not be run to reach an equilibrium state of the oceanic circulation. The COSMOS simulations need a spin-up phase on the order of 5000 years for deep oceans (Stepanek and Lohmann 2012). More experiments and experiments with different models are necessary to establish additional confidence in the results. However, with the computing resources currently available, it is impossible to cover all these considerations.

Acknowledgments This study was supported and funded by German Federal Ministry of Education and Research (BMBF) research project Central Asian Climate Dynamics, "CADY" as a part of the joint research program "CAME-Central Asia: Monsoon Dynamics and Geo-Ecosystems". The authors thank the individual CADY/ CAME teams for permanent support and fruitful discussions. Further we thank Ingo Kirchner, Christian Stepanek and Edoardo Mazza for their interesting and helpful discussions. BF expresses his gratitude to Dagmar Müller for her support during production period of this manuscript. The computational resources were made available by the German Climate Computing Center (DKRZ) through support from the BMBF and the computer facilities at Freie Universität Berlin (ZEDAT). The NCEP and GPCP data was provided by the NOAA/OAR/ESRL PSD, Boulder, CO, USA, from their Web site at http://www.esrl.noaa.gov/psd/. 
Open Access This article is distributed under the terms of the Creative Commons Attribution 4.0 International License (http://creativecommons.org/licenses/by/4.0/), which permits unrestricted use, distribution, and reproduction in any medium, provided you give appropriate credit to the original author(s) and the source, provide a link to the Creative Commons license, and indicate if changes were made.

\section{References}

Anderson DLT, Gill AE (1975) Spin-up of a stratified ocean, with applications to upwelling. Deep Sea Res Oceanogr Abstr 22(9):583-596

Baines P, Palmer T (1990) Rationale for a new physically based parameterization of subgrid scale orographic effects. Technical report, Research Department, CSIRO Division of Atmospheric Research, Aspendale, Australia

Boos WR, Kuang Z (2010) Dominant control of the south Asian monsoon by orographic insulation versus plateau heating. Nature 463(7278):218-222

Boos WR, Kuang Z (2013) Sensitivity of the south Asian monsoon to elevated and non-elevated heating. Sci Rep 3:1192

Bothe O, Fraedrich K, Zhu X (2011) Large-scale circulations and Tibetan Plateau summer drought and wetness in a high-resolution climate model. Int J Climatol 31(6):832-846

Broccoli AJ, Dahl KA, Stouffer RJ (2006) Response of the ITCZ to northern Hemisphere cooling. Geophys Res Lett 33(1):L01702. doi:10.1029/2005GL024546

Chakraborty A, Nanjundiah RS, Srinivasan J (2002) Role of Asian and African orography in Indian summer monsoon. Geophys Res Lett 29(20):1989

Cheng W, Chiang JCH, Zhang D (2013) Atlantic Meridional Overturning Circulation (AMOC) in cmip5 models: Rep and historical simulations. J Clim 26(18):7187-7197

Chiang J, Bitz C (2005) Influence of high latitude ice cover on the marine Intertropical Convergence Zone. Clim Dyn 25(5):477-496

Chiang JCH, Cheng W, Bitz CM (2008) Fast teleconnections to the tropical Atlantic sector from Atlantic thermohaline adjustment. Geophys Res Lett 35(7):L07704

Ding Q, Wang B (2005) Circumglobal teleconnection in the northern hemisphere summer*. J Clim 18(17):3483-3505

Flohn H (1968) Contributions to a meteorology of the tibetan highlands. Paper 130, National Environmental Satellite Center, ESSA, Colorado State University Fort Collins, Colorado

Gregory JM, Dixon KW, Stouffer RJ, Weaver AJ, Driesschaert E, Eby M, Fichefet T, Hasumi H, Hu A, Jungclaus JH, Kamenkovich IV, Levermann A, Montoya M, Murakami S, Nawrath S, Oka A, Sokolov AP, Thorpe RB (2005) A model intercomparison of changes in the Atlantic thermohaline circulation in response to increasing atmospheric $\mathrm{CO}_{2}$ concentration. Geophys Res Lett 32(12):L12703

Gu W, Li C, Li W, Zhou W, Chan JCL (2009) Interdecadal unstationary relationship between nao and east China's summer precipitation patterns. Geophys Res Lett 36(13):L13702

Hannachi A, Turner A (2013) Isomap nonlinear dimensionality reduction and bimodality of Asian monsoon convection. Geophys Res Lett 40(8):1653-1658

Heckley W A, Gill AE (1984) Some simple analytical solutions to the problem of forced equatorial long waves. Q J R Meteorol Soc 110(463):1477-870X

Held IM, Ting M (1990) Orographic versus thermal forcing of stationary waves: the importance of the mean low-level wind. J Atmos Sci 47(4):495-500

Hofer D, Raible CC, Stocker TF (2011) Variations of the Atlantic Meridional Overturning Circulation in control and transient simulations of the last millennium. Clim Past 7(1):133-150
Holton JR, Hakim GJ (2012) An introduction to dynamic meteorology, 5th edn. Academic Press, Waltham

Hoskins BJ, Karoly DJ (1981) The steady linear response of a spherical atmosphere to thermal and orographic forcing. J Atmos Sci 38(6): 1179-1196

Jungclaus JH, Lorenz SJ, Timmreck C, Reick CH, Brovkin V, Six K, Segschneider J, Giorgetta MA, Crowley TJ, Pongratz J, Krivova NA, Vieira LE, Solanki SK, Klocke D, Botzet M, Esch M, Gayler V, Haak H, Raddatz TJ, Roeckner E, Schnur R, Widmann H, Claussen M, Stevens B, Marotzke J (2010) Climate and carboncycle variability over the last millennium. Clim Past 6(5):723-737

Kripalani RH, Oh JH, Chaudhari HS (2007a) Response of the East Asian summer monsoon to doubled atmospheric $\mathrm{CO}_{2}$ : coupled climate model simulations and projections under IPCC AR4. Theor Appl Climatol 87(1-4):1-28

Kripalani RH, Oh JH, Kulkarni A, Sabade SS, Chaudhari HS (2007b) South Asian summer monsoon precipitation variability: coupled climate model simulations and projections under IPCC AR4. Theor Appl Climatol 90(3-4):133-159

Legatt R, Polyakov IV, Bhatt US, Zhang X, Bekryaev RV (2012) North Atlantic variability driven by stochastic forcing in a simple model. Tellus A 64:18695

Liu Y, Wu G, Ren R (2004) Relationship between the subtropical anticyclone and diabatic heating. J Clim 17(4):682-698

Liu Y-H, Henderson GM, Hu C-Y, Mason AJ, Charnley N, Johnson KR, Xie S-C (2013) Links between the east Asian monsoon and North Atlantic climate during the 8200 year event. Nat Geosci 6(2):117-120

Lott F, Miller MJ (1997) A new subgrid-scale orographic drag parametrization: its formulation and testing. Q J R Meteorol Soc 123(537):101-127

Marsland SJ, Haak H, Jungclaus JH, Latif M, Roske F (2003) The Max-Planck-institute global ocean/sea ice model with orthogonal curvilinear coordinates. Ocean Model 5(2):91-127

Marzin C, Kallel N, Kageyama M, Duplessy J-C, Braconnot P (2012) Glacial fluctuations of the Indian monsoon and their relationship with North Atlantic abrupt climate change: new data and climate experiments. Clim Past Discuss 8(6):6269-6308

McManus JF, Francois R, Gherardi JM, Keigwin LD, Brown-Leger $S$ (2004) Collapse and rapid resumption of Atlantic Meridional Circulation linked to deglacial climate changes. Nature 428(6985):834-837

Palmer TN (1994) Chaos and predictability in forecasting the monsoons. Indian Nat Sci Acad 60:57-66

Park H-S, Chiang JCH, Bordoni S (2011) The mechanical impact of the Tibetan Plateau on the seasonal evolution of the south Asian monsoon. J Clim 25(7):2394-2407

Polanski S, Fallah B, Befort DJ, Prasad S, Cubasch U (2014) Regional moisture change over India during the past millennium: a comparison of multi-proxy reconstructions and climate model simulations. Glob Planet Change 122:176-185

Rahmstorf S (2002) Ocean circulation and climate during the past 120,000 years. Nature 419(6903):207-214

Rajagopalan B, Molnar P (2013) Signatures of Tibetan Plateau heating on Indian summer monsoon rainfall variability. J Geophys Res Atmos 118(3):1170-1178

Rodwell MJ, Hoskins BJ (2001) Subtropical anticyclones and summer monsoons. J Clim 14(15):3192-3211

Roeckner E, Brokopf R, Esch M, Giorgetta M, Hagemann S, Kornblueh L, Manzini E, Schlese U, Schulzweida U (2006) Sensitivity of simulated climate to horizontal and vertical resolution in the echam5 atmosphere model. J Clim 19(16):3771-3791

Saito K, Yasunari T, Takata K (2006) Relative roles of large-scale orography and land surface processes in the global hydroclimate. Part II: impacts on hydroclimate over eurasia. J Hydrometeor 7(4):642-659 
Saulire J, Brayshaw DJ, Hoskins B, Blackburn M (2011) Further investigation of the impact of idealized continents and sst distributions on the northern hemisphere storm tracks. J Atmos Sci 69(3):840-856

Stepanek C, Lohmann G (2012) Modelling mid-pliocene climate with cosmos. Geosci Model Dev 5(5):1221-1243

Stocker T, Qin D, Plattner G-K, Tignor M, Allen S, Boschung J, Nauels A, Xia Y, Bex V, Midgley P (2013) IPCC, 2013: climate change 2013: the physical science basis. Contribution of working group I to the fifth assessment report of the intergovernmental panel on climate change. Technical report, Cambridge University Press, Cambridge, United Kingdom and New York, NY, USA

Stouffer RJ, Yin J, Gregory JM, Dixon KW, Spelman MJ, Hurlin W, Weaver AJ, Eby M, Flato GM, Hasumi H, Hu A, Jungclaus JH, Kamenkovich IV, Levermann A, Montoya M, Murakami S, Nawrath S, Oka A, Peltier WR, Robitaille DY, Sokolov A, Vettoretti G, Weber SL (2006) Investigating the causes of the response of the thermohaline circulation to past and future climate changes. J Clim 19(8):1365-1387

Sun J, Wang H (2012) Changes of the connection between the summer North Atlantic oscillation and the east Asian summer rainfall. J Geophys Res 117(D8):D08110

Tang H, Eronen JT, Micheels A, Ahrens B (2013a) Strong interannual variation of the Indian summer monsoon in the Late Miocene. Clim Dyn 41(1):135-153

Tang H, Micheels A, Eronen JT, Ahrens B, Fortelius M (2013b) Asynchronous responses of East Asian and Indian summer monsoons to mountain uplift shown by regional climate modelling experiments. Clim Dyn 40(5-6):1531-1549

Tang H, Micheels A, Eronen J, Fortelius M (2011) Regional climate model experiments to investigate the Asian monsoon in the late miocene. Clim Past 7(3):847-868

Turner AG, Hannachi A (2010) Is there regime behavior in monsoon convection in the late 20th century? Geophys Res Lett 37:L16706
Vellinga M, Wood RA (2002) Global climatic impacts of a collapse of the Atlantic thermohaline circulation. Clim Change 54(3):251-267

Wang YJ, Cheng H, Edwards RL, An ZS, Wu JY, Shen CC, Dorale JA (2001) A high-resolution absolute-dated late pleistocene monsoon record from Hulu Cave, China. Science 294(5550):2345-2348

Woollings T, Gregory JM, Pinto JG, Reyers M, Brayshaw DJ (2012) Response of the North Atlantic storm track to climate change shaped by ocean-atmosphere coupling. Nat Geosci 5(5):313-317

Wu G, Liu Y (2003) Summertime quadruplet heating pattern in the subtropics and the associated atmospheric circulation. Geophys Res Lett 30(5)

Wu G, Liu Y, He B, Bao Q, Duan A, Jin F-F (2012) Thermal controls on the Asian summer monsoon. Sci Rep 2:404

Wu G-X (1984) The nonlinear response of the atmosphere to large-scale mechanical and thermal forcing. J Atmos Sci 41(16):2456-2476

Wu GX, Liu Y, Zhu X, Li W, Ren R, Duan A, Liang X (2009) Multiscale forcing and the formation of subtropical desert and monsoon. Ann Geophys 27(9):3631-3644

Ya G, Huijun W, Shuanglin L (2013) Influences of the Atlantic ocean on the summer precipitation of the southeastern Tibetan Plateau. J Geophys Res Atmos 118(9):3534-3544

Yanni M, Wu G-X (2006) Effects of the Tibetan Plateau, in the Asian monsoon. Springer, Berlin

Yasunari T, Saito K, Takata K (2006) Relative roles of large-scale orography and land surface processes in the global hydroclimate. Part I: impacts on monsoon systems and the tropics. J Hydrometeorol 7(4):626-641

Zhang R, Delworth TL (2006) Impact of Atlantic multidecadal oscillations on India/Sahel rainfall and Atlantic hurricanes. Geophys Res Lett 33(17):L17712 